Manosevitz. M. Behavioral heterosis: Food competition in mice. Journal of Comparative \& Physiological Psychology. 1972. 79. 46-50.

Price. E. O. Novelty-induced self-food deprivation in wild and semi-domestic deer mice (Peromyscus maniculatus bairdii). Behaviour, 1972, 41, 91-104.

Price. E. O.. \& Loomis. S. Maternal influence on the response of wild and domestic Norway rats to a novel environment. Developmental Psychobiology 1973, in press.

Robinson. R. Genetics of the Noruay rat. Oxford: Pergamon Press. 1965.

Schlesinger, K., \& Wimer. R. Genotype and conditioned aroidance learning in the mouse. Journal of Comparative \& Physiological Psychology, 1967, 63, 139-141.

Smart. J. L. Trail-and-error behavior of inbred and $F_{1}$ hybrid mice. Animal Behaviour. 1970, 18. 445-453.

Stone. C. P. Wildness and savageness in rats of different strains. In $\mathrm{K}$. S. Lashley (Ed.). Studies in the dynamics of behavior.
Chicago: Lniversity of Chicago Press. 19.32.

Thorpe. W. H. Learning and instinct in animals London: Methuen, 1963.

Tighe, T. J. A handling device for small animals. Journal of the Experimental Analvsis of Behavior. 1965,8,261-262.

Tinbergen. N. Animal behavior. New York: Time. Inc.. 1965

Weisman. R. G.. Denny. M. R.. \& Zerbolio, D. J. Discrimination based on differential nonshock confinement in a shuttlebox. Journal of Comparative \& Physiological Psychology. 1967.63. 34-38.

\section{NOTE}

1. Personal communication. Prof. L. O. Price. Department of Forest Zoology. Syracuse Lniversity. 1973.

(Received for publication June 11. 1973.)

\title{
Chemical and electrical stimulation of the rat lateral hypothalamus*
}

\author{
NEIL M. KIRSCHNER \\ Bowling Green State Lniversity, Bow'ling Green. Ohio 43402 \\ and \\ ROBERT A. LEVITT \\ Southern Illinois Liniversity. Carbondale, Ill. 62901
}

In a preliminary study, it was not found possible to obtain clear-cut data on the interaction between chemical and electrical stimuli, both applied to the same locus in the lateral hypothalamus. In a subsequent study, the sites in the lateral hypothalamus from which water ingestion can be elicited by electrical or chemical stimulation of the brain were found to have little overlap. However, chemical stimulation drinking sites in the zona incerta and lateral hypothalamus were found to all also be sites from which electrical self-stimulation could be elicited. Since nondrinking sites to chemical stimulation could also be found in this area and were also self-stimulation sites, no specific relationship between chemically elicited drinking and electrical self-stimulation can be drawn.

Some of the most interesting findings to be reported in the physiological literature during the past two decades concern the demonstrated ability to elicit consummatory behaviors which are stimulus bound to the application of an appropriate chemical or electrical stimulant to specific subcortical loci. The application of a chemical stimulant to subcortical loci has been found to elicit eating and drinking behaviors (Grossman. 1960), as well as stimulus-bound sexual behavior (Fisher, 1956). Similar behaviors have been elicited upon the application of an electrical stimulant to selected neural areas (Miller. 1960: Caggiula \& Hoebel. 1966: Mogenson \& Sevenson,

*Supported by USPHS Research Grant MH-14381 and by the Office of Research and Projects of Southern Illinois University at Carbondale. Send reprint requests to Robert $A$. Levitt.
1966). Related to these findings is the observation that electrical stimulation applied to many areas of the brain can serve as a very potent reinforcer. Olds and Milner (1954) reported high rates of responding in the Skinner box situation. with only short trains of electrical pulses delivered to a subcortical area serving as the reinforcer. This barpressing operant response was later termed self-stimulation (S-S) by Brady (1958). Since first reported. S-S has been obtained from many subcortical areas and from all species tested. It is interesting to note that at all neural sites where stimulus-bound consummatory behaviors have been elicited upon the application of an electrical stimulus. S-S behavior is also found (Margules \& Olds. 1962: Caggiula \& Hoebel. 1966: Coons \& Cruce. 1968). The study to be reported attempted to examine the interaction between electrical and chemical modes of stimulation.

Several exploratory investigations have preceded the experiment to be reported. These investigations employed a chemode technique developed by Fisher (1969), which allows for simultaneous electrical and chemical stimulation at the same neural site. or either mode of stimulation alone. Using this technique. an attempt was made to determine whether an anticholinergic chemical (atropine or scopolamine), which had been previously found to block cholinergically induced chemical drinking (Stein \& Seifter, 1962), could selectively block electrically induced drinking upon its application to the subcortical electrical drinking site. Both a self-stimulatory and an automatically delivered electrical stimulus paradigm were investigated. Under the S-S paradigm. only Ss who both self-stimulated and drank to the self-delivered stimulus were employed. Under the automatic delivery: paradigm. only Ss who displayed stimulus-bound 
drinking behavior to current delivered on a 30 -sec "on." 60-sec "off" sechdule were employed.

The results of these investigations indicated the following: (1) Under the S-S paradigm, the mere removal and replacement of the stimulating electrode, which was necessary in order to determine the effects of the chemical application. was alone enough to depress the $\mathrm{S}-\mathrm{S}$ response and consequently the stimulus-bound drinking behavior. Thus, the effects of the chemical on electrical drinking could not be determined through the techniques employed. (2) Under the automatic delivery paradigm, the blocking effect of a $2.5-\mu \mathrm{l} / \mu \mathrm{g}$ solution of atropine was no greater than the blocking effect of centrally applied distilled water, although much variability was found in the data.

From the results of these investigations, it was decided that the techniques being employed could not be used to answer the questions at issue. Thus, it was decided to study the interaction between chemical and electrical stimulation at a more primitive level, whether the neural loci for consummatory behaviors elicited by these two modes of stimulation were identical. More specifically, a study was conducted to determine whether electrically induced drinking could be obtained from positive chemical drinking sites. Furthermore, the question of whether S-S behavior could be selectively obtained from chemical drinking sites, as had been previously reported at electrical drinking sites (Mogenson \& Stevenson, 1960), was also examined.

\section{METHOD}

\section{Subjects, Surgery, and Stimulation Techniques}

A chemode (an insulated hollow guide shaft developed by Fisher, 1969) was aimed at the selected neural locus and was stereotaxically implanted in 38 adult male hooded rats, weighing $200-350 \mathrm{~g}$. under Nembutal anesthesia $(50 \mathrm{mg} / \mathrm{kg})$. From the neural locus under examination $(A+5.6$. L 1.3. -1.0 to -3.5 ; DeGroot. 1954), which initiates at the zona incerta and extends ventrally through the lateral hypothalamus. we have been able to elicit both chemically and electrically induced drinking in pilot studies (using different Ss for each mode of stimulation). Following surgery, all Ss were given at least a 3-day recovery period.

The source of electrical stimulation was a brief-pulse square-wave stimulator (Grass BPS1). Current delivered was bipolar in nature, with the implanted guide shaft and an insulated stimulating electrode serving as the two poles. The stimulating electrode consisted of an adjustable 31-ga wire, which. except for a $1 / 2-m m$ exposed surface at its tip, was insulated throughout its length. Electrical stimulation was applied centrally by inserting the electrode into the implanted guide shaft and lowering it in a vertical column to a depth approximately $1 / 4 \mathrm{~mm}$ below the depth of a previously found positive chemical drinking site. The electrode was placed at this depth so that its $1 / 2-\mathrm{mm}$ exposed surface would be centered at the point at which the chemical stimulant was applied. Chemical stimulus consisted of crystals. which were finely ground with a mortar and pestle and tamped (4-5 tamps) into a 30-ga cannula and applied centrally through the implanted guide shaft.

\section{Test Chambers}

All tests for S-S and stimulus-bound electrical drinking were conducted with the $S$ in a metal cage. 18 in. square $\times 13 \frac{1}{1}$ in. high. During S-S tests, a metal lever and a calibrated water bottle habing a metal water spout were present in the cage. During tests for stimulus-bound electrical drinking. the lever was removed. All chemical drinkirg tests were conducted with the $S$ in a metal cage, $8 \times 10 \times 6$ in.. with only a calibrated water bottle having a metal spout available in the cage.

\section{Drug}

The cholinergic stimulant employed in this study was carbachol (choline chlorine sarbamate).

\section{Procedure}

Each of 29 Ss was tested for drinking to carbachol (while sated) at the most dorsal position of the implant site. The 9 remaining $S$ s were employed in a control group to be discussed below. If the $S$ did not drink to a $4-\mathrm{ml}$ criterion in $1 \mathrm{~h}$ after chemical stimulation, the chemical connector was lowered in $1 / 2-m m$ steps in a vertical column until either a positive site was located or the ventral limit of the region to be stimulated was reached. A minimum of $48 \mathrm{~h}$ was interspersed between chemical stimulation sessions, in order to allow residual chemical effects to dissipate. Those $\mathrm{Ss}$ in which a positive chemical drinking site was located were then tested at that site for stimulus-bound electrical drinking at least $48 \mathrm{~h}$ after their previous chemical stimulation (all other Ss were eliminated from the study). Each $S$ was tested for electrical drinking for a period of $100 \mathrm{~min}$, with the electrical pulses automatically delivered on a schedule of $30 \mathrm{sec}$ "on," $60 \mathrm{sec}$ "off." Water consumption was measured every $20 \mathrm{~min}$. Those Ss who displayed drinking behavior contingent upon the electrical stimulation were run under these conditions until 60 min of drinking data were collected (starting from the onset of drinking). Those Ss who displayed a forward moving "searching" behavior (Valenstein, Cox, \& Kakolewski, 1968) but did not drink were retested for electrical drinking at least $48 \mathrm{~h}$ after the initial test (all other Ss were tested only once). A period of at least $24 \mathrm{~h}$ separated each S's last session of electrical stimulation and a subsequent chemical drinking retest procedure. If a previously positive chemical site tested negative during the retest, the chemical retesting procedure was repeated $48 \mathrm{~h}$ later. Only data from Ss for which one of these two retest procedures proved positive were employed. All Ss who retested positive upon chemical stimulation were subsequently tested (after at least a 48-h "rest" period) for S-S at the site of previous chemical and electrical tests. The stimulus duration for the S-S tests was $0.5 \mathrm{sec}$. with the current intensity adjusted in order to determine the level that elicited maximal responding. Each $\mathrm{S}$ was tested for S-S for a period of $90 \mathrm{~min}$ on a maximum of 3 successive days. If an $\mathrm{S}$ displayed at least 100 barpresses during any $10-\mathrm{min}$ recording period on any of these 3 days, it was allowed to stimulate until the level of responding reached a plateau (stopped increasing).

Besides the main experimental group. an S-S control group of nine Ss was employed. Each of these $S s$ was initially tested for chemical drinking at a depth of $-1.5 \mathrm{~mm}$ (DeGroot, 1954) at the implant site. If the site proved negative. the $\mathrm{S}$ was tested $48 \mathrm{~h}$ later for S-S. using the same procedure employed with the main experimental group. If the initial chemical test was positive. the $\mathrm{S}$ was retested at least $48 \mathrm{~h}$ later with the connector lowered $1 / 2 \mathrm{~mm}$ in a vertical column. This procedure was continued until either a negative site was found or the ventral limit of the anatomical area of interest was reached. Subsequent to the S-S tests (after at least $48 \mathrm{~h}$ ). each $\mathrm{S}$ was retested with the chemical stimulant in order to reestablish its negativity for cholinergic drinking. Only data from Ss who retested negative were employed in the data analysis.

\section{RESULTS}

Sixteen of the 29 Ss $(55.2 \%$ ) that originally composed the main experimental group drank to criterion upon chemical stimulation during both the initial chemical testing at a particular depth and one of the two chemical 
retests at that site. Three Ss of this positive chemical site group emitted blood or cerebrospinal fluid from their implants during subsequent S-S testing, and. therefore. the data from these Ss were withdrawn from the study: Thus. the data below concern only the remaining 13 Ss that retested positive upon the application of the chemical stimulant. Only $2\left(15.3^{c}\right)$ of these Ss displayed electrical drinking when tested (both emitted the drinking behavior on the first testing session). Concerning the amount of water consumed by these Ss. 1 drank an average of $3 \mathrm{ml}$ per $20-\mathrm{min}$ period and the other drank an average of $2.3 \mathrm{ml}$. Concerning the S-S tests. 12 of these 13 Ss (92.3\%) displayed S-S behavior above the criterion level. The one negative S-S S never pressed the bar more than 10 times during any $10-\mathrm{min}$ recording period. The average number of leverpresses for these 12 Ss. considering only their highest $10-\mathrm{min}$ rates, was 307 leverpresses per 10-min period.

Six of the nine Ss $(66.7 \%)$ that composed the S-S control group tested negative to chemical stimulation during both the initial chemical test at a particular depth and the subsequent retest. S-S was displayed by five $(83.3 \%)$ of these six Ss. The one negative S-S S never pressed the lever more than 10 times during any $10-\mathrm{min}$ testing sessions. The average number of leverpresses for these five Ss. considering only their highest 10 -min rates, was 365 leverpresses per 10-min period.

\section{Histology}

Histological verification of the intended implant sites is available for 11 of the 13 Ss comprising the main experimental group and all 6 of the S-S control group. Each of these Ss was sacrificed and perfused with $10 \%$ Formalin solution, with verification based upon 40-micra frozen sections of brain tissue stained with cresyll violet. For both groups, all implants were located in an area initiating at the zona incerta and extending ventrally through the lateral hypothalamic area. All but one of the stimulating sites fell within this area (5.4-5.6 $\mathrm{mm}$ anterior to the interaural line; $0.5-2.0 \mathrm{~mm}$ lateral to the midsaggital sinus). One of the Ss was found to be stimulated at $6.2 \mathrm{~mm}$ anterior to the interaural line. and the cannula for this $S$ terminated at the ventral portion of the lateral ventrical. This was the one $S$ in the cholinergic drinking group which did not display S-S behavior to criterion.

\section{DISCUSSION}

The data from this study appear to indicate, at least within the limits of the stimulation techniques employed and the subcortical loci stimulated. that there is not an identity between sites from which electrically induced and chemically induced drinking behavior can be obtained. The validity of this statement rests upon the supposition that the neural fields activated in this experiment by these two different modes of stimulation possess a major degree of overlap. Chemical stimulation data employing powdered dve (Maclean. 1957). microliter injection (Myers, 1966). and flourescence tracing techniques (Routtenberg. Sladek. \& Bondareff. 1968). as well as several sources of electrical stimulation data (Valenstein \& Beer. 1961:
Schaltenbrand. 1965: Valemstein. 1960). appear to indicate that both modes of stimulation tend to activate a relatively restricted area. ranging approximately from 1 to $2 \mathrm{~mm}$ from the cannula or electrode site. Thus. the supposition appears to be supported. A large number of alternative hypotheses are available concerning possible explanations for the found nonidentity between chemical and electrical drinking sites. none of which ean be conclusively supported by the data now arailable in the literature: speculation would thus appear to be premature.

Considering the results of histological verification. all Ss that displayed chemically induced drinking in the area of the zona incerta and lateral hypothalamus also displayed S-S. These data are consistent with the previously reported data from studie: where drive-related consummatory behaviors are elicited by electrical stimulation. in that. at sites where these behaviors are elicited. S-S is always found. It is interesting to note that five of the six nonchemical drinking Ss also displaved S-S behavior. The most direct inference from these results is that S-S is elicitable from this area regardless of whether chemically induced drinking is also elicitable from these sites. It should be noted that there remains the possibility that drive-related behaviors other than those measured in this study are elicitable from the negative chemical drinking sites employed.

\section{REFERENCES}

Brady, J. V. The paleocortex and behavior motivation. In $\mathrm{H}$ Harlow and $\mathrm{C}$. Woolsey (Eds.), Biological and biochemical bases of behavior. Madison: University of Wisconsin Press. 1958.

Caggiula, A. R. \& Hoebel, B. G. "Copulation-reward site" in the posterior hypothalamus. Science, $1966,153,1284-1285$.

Coons, E. E., \& Cruce, J. A. F. Lateral hypothalamus: Food current intensity in maintaining self-stimulation of hunger Science, 1965, 159, 1117-1119.

DeGroot, $J$. The rat forebrain in stereotaxic coordinates. Journal of Transactions of the Royal Netherlands Academy of Science, $1954,52,1.40$.

Fisher, A. E. Maternal and sexual behavior induced by intracranial chemical stimulation. Science, 1956, 154, 228 .

Fisher, A. E. The role of limbic structures in the central regulation of feeding and drinking behavior. In P. J. Morgane (Ed.), Neural regulation of food and uater intake. Annals of the New York Academy of Sciences, 1969, 157, 894-901.

Grossman, S. P. Eating or drinking elicited by direct adrenergic or cholinergic stimulation of the hypothalamus. Science. 1960, 132, 301-302.

Maclean, P. D. Chemical and electrical stimulation of the hippocampus in unrestrained animals, I. Archives of Neurology \& Psychiatry, 1957, 78, 128-142.

Margules, D. L., \& Olds, J. Identical feeding and reward systems in the lateral hypothalamus of rats. Science, 1962. 135. $374-375$.

Miller N. E. Motivational effects of brain stimulation and drugs. Federation Proceedings, 1960, 19, 846-854.

Mogenson, G. J., \& Stevenson, J. A. F. Drinking and self-stimulation with electrical stimulation of the lateral hypothalamus. Physiology \& Behavaior, 1966, 1, 251-254.

Myers, R. D. Injection of solutions into cerebral tissue: Relation between volume and diffusion. Physiology \& Behavior, 1966. $1,171 \cdot 174$

Olds, J., \& Milner, P. Positive reinforcement produced by electrical stimulation of septal area and other regions of the rat brain. Journal of Comparative \& Physiological Psychology, $1954,47,419-427$.

Routtenberg, A., Sladek, J., \& Bondareff, W. Histochemical flourescence after application of neurochemicals to caudate nucleus and septal area in vivo. Science, 1965, 161.272-274.

Schaltenbrand, G. The effects of stereotaxic electrical stimulation in the depth of the brain. Brain, 1965, 88, 835-840.

Stein, L., \& Seifert, J. Muscarinic synapses in the hypothalamus American Journal of Physiology, 1962, 202, 751-756.

Valenstein, E. S. The anatomical locus of reinforcement. In E. Stellar and J. M. Sprague (Eds.), Progress in physiological psychology. New York: Academic Press, 1966.

Valenstein, E. S., \& Beer, B. Unipolar and bipolar electrodes in self-stimulation experiments. American Journal of Physiology, $1961,201,1181-1186$.

Valenstein, E S Cox V. C., \& Kakolewski, J. W. Modification of motivated behavior elicited by electrical stimulation of the hypothalamus. Science, 1968, 151, 1119-1121.

(Received for publication June 6.1973.) 